\title{
Restructuring and the Proper Syntactic Analysis *
}

\author{
Hong-Pin Im ** \\ (Seoul National University, Korea)
}

\begin{abstract}
This paper aims to make it clear that syntactic analysis should be based on the lexical information given in the lexicon. For this purpose, lexical information of the syntactic argument is to be taken the form like [vp NKP, , DKP, AKP] for the ditransitive verb give in English. The argument structure projects to syntactic structure. The NKP in this structure becomes VP-subject, but there is another subject called S-subject (Sentence-Subject) below S node. This amounts to Two-Subject Hypothesis for English. Between these two subjects, there intervene Conjugation-Like Elements, enriched by close examination of English verbal conjugation.

Two-Subject Hypothesis perfectly accounts for peculiarities of the Expletive There (ET) construction. Restructuring can also explain the so-called Long Distance Wh-interrogative without introducing Wh-movement, and it can also explain why the imperative verbs are taking the base forms. It can also explain the characteristics of adjective imperatives by the same principles as applied to verbal imperatives. We try to deal with the other subtle problems, to get fruitful results. Restructuring approach, we think, provides more convincing explanations than the movement one.
\end{abstract}

Keywords: restructuring, sentence type, Two-Subject Hypothesis, Conjugation-Like Element, ET construction, Long Distance Wh-interrogatives, adjective imperatives

\section{Introduction}

\section{$1.1 \mathrm{Goal}$}

The goals of this paper are twofold. The first is to make it clear that the phrase structures which the so-called Generative Transformational Grammar (TG) has hitherto set up are intrinsically insufficient, and to suggest alternatives based on the lexical information given in the lexicon. The argument structure consists of syntactic arguments with the case and other

\footnotetext{
* Owing to anonymous reviewers and the proofreader of this Journal, we could reconsider theoretical insufficiencies, make correction about practical mistakes in application and English expressions. Thereby this paper has made considerable improvements. I would like to express my deep gratitude to the anonymous reviewers and proofreaders. But the errors are only of writer's responsibility.

** Dr. Hong-Pin Im: Professor Emeritus, Department of Korean Language and Literature, College of Humanities, Seoul National University, Korea. Main Books: Restructuring in Korean, The Topic in Korean and the Syntactic Structures, A Study on the Reflexives in Korean, etc. E-mail: imhp@snu.ac.kr.
} 


\section{Hong-Pin Im}

properties to be useful to make syntactic structure and semantic interpretation.

We have already postulated the argument structure of which the cases are given in the lexicon of Korean data. For example, as to the ditransitive verb $j u$ - 'give' in Korean, the argument structure is given like [NKP, DKP, AKP, ], where NKP stands for Nominative Case Phrase, DKP Dative Case Phrase and AKP Accusative Case Phrase. This position is called Case Lexicalist Hypothesis in Im (2008; 2018a, b). If the processes like the case percolation and the case matching occur in syntax (Schütze, 2001), the relevant cases should be given previously.

In this paper, we are going to extend the argument structures as applied to Korean data even to English. The cases are given to arguments of verbs and other lexical heads in the lexicon, as far as the argument cases are concerned. ${ }^{\circledR}$ Only the order of arguments in English is different from Korean. The same is true for the other European languages. For example, one argument structure of English ditransitive verb give is provided with the structure like [ ${ }_{\mathrm{vP}} \mathrm{NKP}$, , DKP, AKP], where the underlined part is the position of verb. This hypothesis can be called NKP (Subject)-Including VP Hypothesis. Since there is another subject under $\mathrm{S}$ node, this amounts to Two-Subject Hypothesis. ${ }^{2}$

TG Grammarians seem to believe that cases are derived from syntactic rules and/or configurations. But this way of approach might seriously distort the case identification and might lead to dissolution of the case system. They cannot provide any satisfactory solution even to the dative construction. They might assign [+objective] to the dative case phrase. But the dative case cannot be identified with the accusative case. Usually, in TG, the other traditional cases except [+subjective] and [+objective] are abandoned not to be touched upon. Such are the cases of the constituent of the subject complement and that of the object complement. $^{(3)}$

Another goal of this paper is to construct syntactic structures on the basis of lexical information given in the lexicon. ${ }^{\oplus}$ At this step, we will rely on the Hypothesis of Variable Medial Projection, previously shown in Im (2008). This implies that the V-projections are determined with recourse to the number of argument(s) given in the lexicon.

\footnotetext{
(1) Many of the McFadden's (2004) 'morphological cases' can be absorbed in lexicon, and many portions of semantic cases can also be absorbed in lexicon, maybe in the form of semantic compatibilities. The percolating (or concordial) and/or matching phenomena of cases will be dealt with in syntax.

2) This might be similar to VP- or vP-Internal Subject Hypothesis. But they are different from our Two-Subject Hypothesis which allows that the two subjects can be different, but such a thing never happens in the former.

(3) The Spec-head agreement works in Chomsky (1995), etc.

(4) As pointed out in the reviewer's notes, this is against the essential principle of Chomskyan syntax which advocates that syntax is the fundamental thing. Regretfully, we do not accommodate the syntactic approaches which try to do syntax independently of lexical information as far as possible. For us at least, lexical information is the critical material for the syntax to work with.
} 


\section{Restructuring and the Proper Syntactic Analysis}

As for conjugation, we set up Conjugation-Like Elements, contrasted with the simple INFL as postulated in Chomskyan syntax. Since VP is not a sentence by itself, there should be an S comprising S-subject and VP-subject. In addition, we posit detailed Conjugation-Like Elements to comprise the practical usages of verbal conjugations in English. Here are mood, tense, S-Aux (Strong-Aux like will, shall, can, must, ought to, etc.), W-Aux (Weak-Aux like do, be able to, have to, be-ing, etc.) and Neg element, etc.

With, above mentioned Case Lexicalist Hypothesis, Hypothesis of Variable Medial Projection, Two-Subject Hypothesis, Subject Precedence Principle and Restructuring, we will explore the syntactic structures of sentence types in English, and some other constructions including the expletive there.

\subsection{The crucial nature of restructuring ${ }^{\mathbb{1}}$}

Restructuring is a sort of reanalysis which changes a given structure to another. Approaches to restructuring can be divided into two kinds: one can be called Transformationalist's Approach, the other Base Generativist's Approach. ${ }^{2}$ At the Transformationalist's Approach, there should be a transformation changing one structure to another radically. On the other hand, the Base Generativist's Approach sees that there should be no transformation involved in restructuring, since the structure is given as such from the very start. $\left.{ }^{(}\right)$

Now look at some examples of Chomsky (1974).

(1) a. Bill took advantage of Mary.

b. [V took][NP [N advantage $]][\mathrm{pP}[\mathrm{P}$ of $]]$

c. Advantage was taken of Mary by Bill.

d. Mary was taken advantage of by Bill.

The idiomatic part of (1a) could be analyzed as (1b). From (1a), two kinds of passive are possible: one is like (1c), the other is like (1d). The latter is due to the restructuring applied to the structure of (1a, b). (1b) as a whole is recognized as one V. In (1b), the categories and boundaries between took and of are in the shadow. The shadow means that the parts are not completely extinct, only treated as 'non-existent', but sometimes works as 'existent' and sometimes as 'non-existent'. When the shadowy parts are treated as 'existent', the structure latent in (1b) shows up and works, and in turn when the shadowy parts are treated as 'non-existent', the structure (1b) does not work.

The following shows syntactic and/or lexical peculiarities with respect to restructuring.

\footnotetext{
(1) As to the concept of restructuring, this paper basically rests upon the ideas proposed in $\operatorname{Im}(2018 \mathrm{a}, \mathrm{b})$ dealing with restructuring in Korean. The tenet and methodology of this paper in principle are not different from that, with some changes in details. While Im (2018a, b) extensively treats Korean data, this paper develops its idea, to apply mainly to English data.

(2) Rizzi (1982), Burzio (1986), Choe (1988), etc. could belong to the former, and Chomsky (1974, 1981), Manzini (1983), Picallo (1985, 1987), Cinque (2006), etc. could belong to the latter (Im, 2018a).

(3) Previous approaches to restructuring are dealt with in $\operatorname{Im}(2018 \mathrm{a}, \mathrm{b})$.
} 


\section{Hong-Pin Im}

(2) a. "John took an/the/this advantage of Mary.

b. *John took advantages of Mary.

c. ${ }^{*}$ John took benefit/merit of Mary.

(2a) and (2b) show that neither definite nor indefinite articles, nor indexicals, nor plural nouns can be used with or as Core Noun (Here, Core Noun is defined as the noun that plays a central role in idioms or collocations). (2c) shows the lexical restrictions. In other words, the idiomatic expression take advantage of means 'utilize', not to mean 'have merits of'. It is conceded that restructuring shows syntactic, semantic, and/or lexical peculiarities. Now let's present the detailed aspects of restructuring as follows.

(3) The detailed aspects of restructuring

a. Restructuring treats 'existent' as 'non-existent' in syntactic categories and boundaries, and vice versa.

b. Restructuring changes given categories and/or configurations to another.

c. Restructuring shows syntactic, semantic, and/or lexical peculiarities, though not always the same thing happens.

d. Restructuring by nature reflects the native speaker's intuitive structure imposed upon the strict syntactic structure.

(3d) loosely defines the restructuring as a psychological process. Native speaker's intuitive ideas about the structure are not so rigorous to accommodate the sophisticated syntactic structure. The point is that the native speaker's intuitive ideas are not always identical to the structures reached on the basis of rules and principles investigated in speculative grammar.

The process involved in restructuring is not that of Chomskyan syntax, since the transformation by nature deals with general categories or features, not with lexical elements. Syntactic rules by nature aim to capture the syntactically-oriented generality between syntactic structures, not lexically-dependent singularities.

Here we will mainly try to deal with problems with regard to the ET construction and sentence types, without recourse to movement. Let's see how restructuring can be applied to these structures below.

\section{Two-Subject Hypothesis and restructuring}

\subsection{Independent sentence is not CP}

Usually in TG the 'Sentence' is categorized as Complementizer Phrase (CP), so much as the embedded sentence is categorized as CP. However, this is seriously defective and gives rise to unexpected ambiguities and wrong predictions. It might be said that the two are roughly similar in nature. However, it should be emphasized that some of the sentence types could not be derived by way of movement and/or merge operations from the base.

Conceptually, CP is a category born to be embedded, whereas 'Sentence' is an independent entity not to be embedded. It might be said that the differences are natural consequences that 


\section{Restructuring and the Proper Syntactic Analysis}

stem from the position where the same entity is situated. However, in practice there is no such sentence as terminated by the form of 'that S', namely there is no such declarative sentence as " "That John is a student".

In the meantime, sentence types have been neglected in the literature. Chomsky (1957) introduced transformational processes like $T q$ and $T w^{(1)}$ to derive Yes/No questions and Wh-interrogatives. But it is not desirable to set up transformations to derive sentence types from a single origin, i.e., from the declarative-like origin. Consider the following.

(4) a. How brilliant Mary is!

b. *Mary is how brilliant.

c. very $\rightarrow$ how (arbitrary lexical rule)

(5) a. What a brilliant girl Mary is!

b. "Mary is what a brilliant girl.

c. very brilliant $\rightarrow$ what a brilliant (arbitrary lexical rule)

Exclamative sentence like (4a) is not derivable from the putative declarative origin like (4b). To derive (4a) from (4b), there must be a rule like (4c). However, $(4 c)$ is nothing but an arbitrary random lexical rule, applied to a lexical item. The operation like (4c) is untenable simply because transformation is a structure-dependent process, not a lexically oriented process. Certainly, (4c) is a lexically motivated rule. The same is true for what (a) exclamative sentence (see Section 5) like (5a). The structure like (5b) is not acceptable, because (5c) also is a lexically motivated rule.

It is unthinkable that the imperative sentence can be derived by simple deletion of the subject of declarative sentence. In practice, we cannot easily get the answer about what the defining characteristics of the declarative sentence should be. By now, the declarative sentence has been thought to be the last product by the base rule and obligatory transformations. But it is not so obvious from where the declarative force comes. ${ }^{(2)}$ In contrast, Whquestions and the ET constructions have been the targets of the fierce debates on the syntactic and semantic properties. But the exact natures are not tangible, because their discussions basically are based on the presupposition that 'sentence' is a sort of CP.

\subsection{Two subject positions in English sentence}

\subsubsection{Argument structures and projections}

Some principles and methods in analyzing syntactic structures are already presented in $\mathrm{Im}$ (2008; 2018a, b). One is the Case Lexicalist Hypothesis that says that as far as lexical cases

\footnotetext{
(1) $T q$ represents the question transformation, and $T w$ represents Wh-transformation. Chomsky (1995:289330) sees English $\mathrm{Q}$ is strong. When $\mathrm{Q}$ is introduced into the derivation, its strong feature must be eliminated by insertion of $\mathrm{Fq}$ in its checking domain.

(2) We deal with the declarative sentence in Section 7. Chomsky $(1995: 332)$ sets up declarative C. It is null variant of $\mathrm{C}$, inserted covertly in a root clause. But it never overtly appears. But for us, 'sentence' does not have $\mathrm{C}$. Thus, strong $\mathrm{Q}$ for interrogative and weak $\mathrm{C}$ for declarative do not make sense.
} 
are concerned, the cases should be given in the lexical information of the lexicon. And the other is the Hypothesis of Variable Medial Projection(s) that says that the number of medial projection(s) should be matched with the number of argument(s) of a predicate (or verb). Let's see two examples of argument structure of Korean and English like the following.

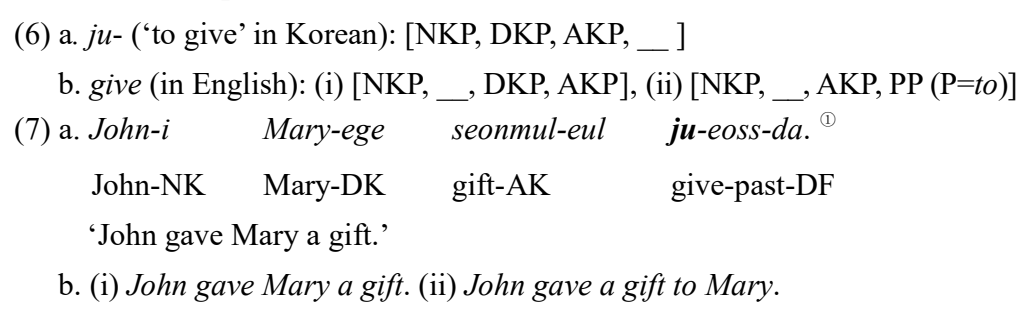

(6a) shows that the argument structure of the Korean verb $j u$ - consists of [NKP (Nominative Case Phrase), DKP (Dative Case Phrase), AKP (Accusative Case Phrase)] and the position of the verb (the underlined part), which demonstrates the character of the $\mathrm{V}$ (Verb) final language. (7a) embodies the argument structure of (6a). The nearly identical structure is proposed in (6bi) for English verb 'to give', but only the position of verb is different, which embodies the character of V2 (Verb Second) language. (7bii) embodies the argument structure of (6bii).

It is noted that in $(6 a, b)$ the NKP is contained in VP, different from the usual practice of TG

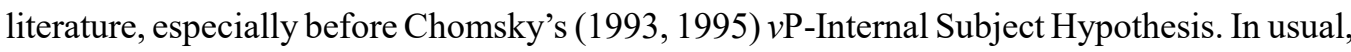
NKP is excluded from VP. However, if NKP is excluded from VP, the NKP's lexical peculiarities cannot be described in the lexicon, and cannot be reflected in the syntax. Even in the $v$ P-Internal Subject Hypothesis, it is unclear where the information of the subject comes from.

As to Chomsky's Case Theory, the argument structure like (6b) might be somewhat surprising. It is because in Chomsky $(1981,1995)$ the cases are syntactically assigned or checked. But it is not so successful. It seems that he does not take much of the dative argument of the verb give, the object complement, i.e., predicate expression that follows a direct object, and subject complement of copular sentence, not to mention the real subject of the ET construction. ${ }^{(2)}$ On the contrary, if we assume that the lexical cases are given in the lexicon like $(6 a, b)$, the complexities and insufficiencies concerning lexical cases ${ }^{(3)}$

\footnotetext{
(1) Here $-i$ of John-i is a Nominative Case Marker (NK), -ege of Mary-ege is a Dative Case Marker (DK), and -eul of seonmul (gift)-eul is an Accusative Case Marker (AK). And the Prefinal Ending (PF) -eoss- of $j u$-eoss- $d a$ 'gave' is a past tense marker [+past], and - $d a$ of $j u$-eoss- $d a$.is a Declarative Final Ending (DF).

(2) If the case of expletive there is assigned or checked by Spec-head agreement, what about the case of the real subject?

(3) Freidin \& Sprouse (1999) distinguish configurational case and lexical case. However, their lexical case seems to be confined to dative case, and their configurational cases are limited to nominative and accusative. For us, even the putative configurational cases are given in the lexicon, such as NKP or AKP in terms of argument structure [NKP, , AKP] of the typical transitive verb.
} 


\section{Restructuring and the Proper Syntactic Analysis}

would be evaporated.

On the basis of the argument structure, we will get the VP structure by way of projections. In Korean, the projection proceeds like (8a) based on (6a) (Im, 2008). (8b) is for English based on (6bi).

(8)

a.

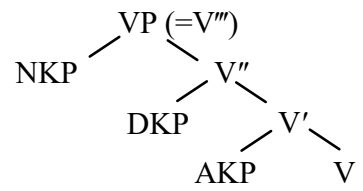

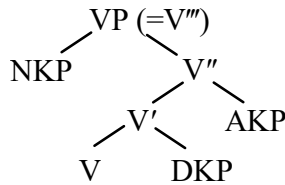

In (8a), VP is to take the Prefinal (PF) projections like honorific, tense, humble markers, etc., and final phrase (FP) consists of Final ending (F) projections formed by declarative, interrogative, imperative, or exclamative makers, etc. Sentence types in V-final language like Korean or others are determined by F projections. Other things being equal, NKP in (8a) can in general be given to the status of S-subject by Subject Precedence Principle.

On the other hand, the situation in ( $8 b)$ is critically different from Korean and Japanese type languages. Sentence types are not determined by conjugation, but by heterogeneous elements like subject-position, Do-support, Subject-Verb (or AUX) inversion, and putative performative elements (Bierwisch, 1980; Searle, 1989), etc. For this purpose, extra-subject and its position are needed in addition to NKP subject of VP. We call this S-subject.

In English-type languages, since the verb in principle ${ }^{(\mathbb{1}}$ carries Conjugation-Like Elements, different from Korean, ${ }^{(2)}$ there is a subtle gap between S-subject and VP-subject. On the other hand, there is no such gap in Korean-type languages, because the conjugated verb does not intervene between S-subject and VP-subject. Considering this feature, English-type languages can be called Two-Subject Languages. ${ }^{3}$ And, this hypothesis can be called TwoSubject Hypothesis. ${ }^{(4)}$

\footnotetext{
(1) In the indicative mood in English, the form of verb varies morphologically according to mood, tense, person and number. But, S-AUX (Strong AUX), negation, number, person, perfect, W-AUX (Weak AUX) are mainly represented by lexical elements.

(2) Korean verb also takes prefinal and/or final endings, but in principle what takes prefinal and/or final endings is VP, not V. By restructuring, the endings are considered to be attached to the verb stem.

(3) For Italian, Cardinaletti (1997) set up two subjects: strong subject and weak subject. Strong subject is realized at SpecAgr $_{S} 1 \mathrm{P}$ (Specifier of $\mathrm{Agr}_{\mathrm{S}} 1 \mathrm{Phrase}$ ), and weak subject is realized at SpecAgr2P. Italian belongs to null subject language, whereas English and French belong to non-null subject language. Following this, since English is not null subject language, English could not belong to two-subject language. However, Cardinaletti (1997) does not take into account of the argument structure of verb, and the information given in the lexicon. If null subject in Italian should be specified in argument structure as in English, the configuration would not be so different from English. In English, the argument structure of expletive there be would be like [there BE NKP PP]. Likewise, in Italian, the argument structure of the expletive $c i$ essere 'there be' could be represented like [ci ESSERE NKP PP]. The difference lies in marginal structure, lexically marked. Nominative case of the real subject can be accounted for by the lexical information given in the lexicon.

(4) The SPEC(IP) Subject Hypothesis (Hale, 1980; Farmer, 1984) and the VP-Internal Subject Hypothesis
} 


\section{Hong-Pin Im}

\subsubsection{Conjugation-Like Elements in English}

Chomsky (1965) set up Aux category in the middle of subject and predicate. It is in Chomsky (1981) that the INFL category was introduced into the syntax, not yet to arrive at setting up the Inflection Phrase (IP) category. Pollock (1989) introduced AgrP and NegP, beside TP, based upon the facts related to the barrier and movement. Usually, this is called 'Split IP' Hypothesis. Chomsky (1995) still further separated AgrP into $\mathrm{Agr}_{\mathrm{S}} \mathrm{P}$ related to subject and $\mathrm{Agr}_{0} \mathrm{P}$ related to object. Pollock (1989) took note of the features number/person, etc., but did not take much of the relevant phenomena, due to "the disappearance of a morphologically 'rich' system of agreement inflection" in English. But, this is too heavily attracted by movement approach.

As to these problems, we set up Conjugation-Like Elements (CLEs) to comprise mood, tense, S-Aux, number, person, perfect, W-Aux in English. The category CLE contains strongAux, weak-Aux, perfect, etc. categories traditionally not contained in typical 'conjugations' in English. If these elements are not included in the category CLE, there is no way to introduce these elements into syntax. It is to be noted that in argument structure there is no room to accommodate mood, tense, modals and aspects, etc. These categories could be effectively described in terms of CLE, including proper conjugations. In other words, mood does not belong to argument structure. Tense also does not belong to argument structure, etc. Thus, these categories are necessary to be dealt with in some other components, e. g. in the CLE in syntax.

In English, each category of CLEs should be set up as independent projection, just like prefinal phrase and FP formed by prefinal and final endings in Korean. The tree diagram in (9) shows the whole picture of the structure of CLEs that a ditransitive verb give in English can have in sentence, and some other relevant categories.

Since it can be acknowledged that the effect of each CLE reaches a whole range of sentences, it is suitable to set up independent phrasal projection for each CLE. ${ }^{(1)}$ For us, the CLE originally indicates individual CLE elements appearing between S-subject and VP-subject, but it also designates the category name comprising whole individual CLEs.

At first, $\mathrm{S}$ (Sentence) is branched into subject and MoodP. The subject under S is S-subject. The mood is divided into [ \pm fact]. If mood selects [ + fact] feature, then $S$ becomes fact mood (or indicative mood). Otherwise, $\mathrm{S}$ becomes subjunctive mood. Tense and S-Aux are affected

(Fukui, 1986; Kitagawa, 1986) are criticized by Tateishi (1994), concerning Japanese multiple subject construction. But our Two-Subject Hypothesis is not concerned with multiple subject construction in Korean or Japanese, etc.

(1) In English, the CLEs do not go over a clause. As in the example like John went to a shop and bought a gift, the tense is confined to each clause, even in the successive reading of two events. In this case, it is considered that each clause has its own CLE maximal projection. Syntactically the structure [+past] [John go to a shop and buy a gift] is not permitted. 


\section{Restructuring and the Proper Syntactic Analysis}

by the selection of mood. As in 'If I were a bird, I could fly to you', the tense following mood shows different morphology. In the majority of cases, the morphologies related to mood are completely neglected roughly during the last 50 years.

(9)

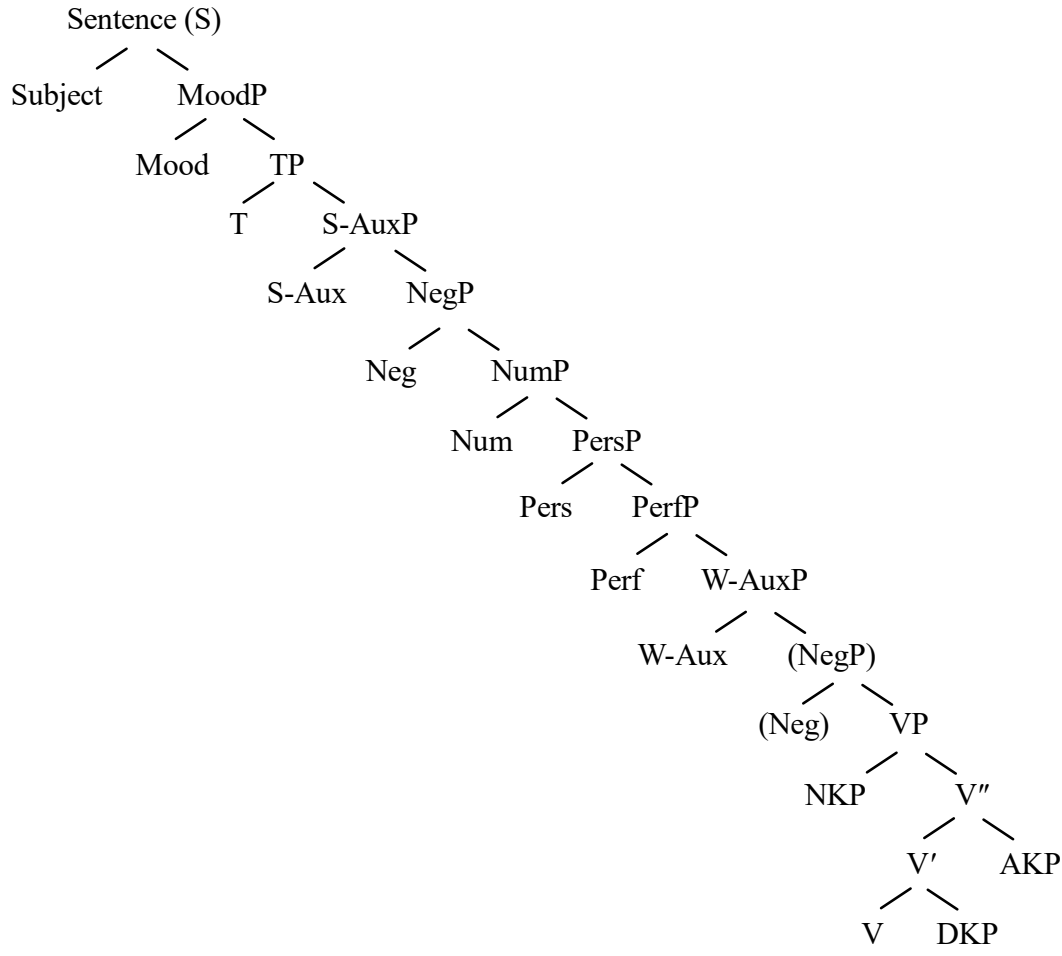

Tense has the $\left[{ }^{\mathrm{p}}\right.$ past $]$ feature. The $[+$ past $]$ feature encompasses the whole range of time before present tense, and the rest range of tense is covered by [-past]. The future in English is expressed by the composition of [-past] feature and S-Aux like will or shall. Under TP (Tense Phrase) comes S-AuxP (Strong Auxiliary Phrase) of which the head is the Aux like will, shall, can, may, must, ought to, etc. not affected by person and number of the subject. Among S-Aux, must and ought to are not affected by the tense morphology.

The analytic or synthetic processes of S-Aux affected by mood and tense are like the following.

(10) a. $[+$ fact $]+[$-past $]+[$ s-Aux WILL $](\leftarrow) \rightarrow$ will

b. $[+$ fact $]+[+$ past $]+[$ s-Aux WILL $](\leftarrow) \rightarrow$ would

c. [-fact $]+[$-past $]+[$ s-Aux WILL $](\leftarrow) \rightarrow$ would

The analytic or synthetic processes are simple and straightforward. (10a) shows the process that the fundamental S-Aux WILL is synthesized with or analyzed into the features of mood and tense. $(10 \mathrm{~b}, \mathrm{c})$ show the similar analytic and/or synthetic process, with different mood and tense features. The will in (10a) is interpreted as 'factive non-past i.e. [-past]' form. 
The (10b) and (10c) are not different in form, but would of (10b) is 'factive past S-Aux', and would of (10c) is 'subjunctive non-past S-Aux'. The forms of CLEs are morphologically defined.

As is well known, the noticeable verbs that show the full conjugation-like forms are the verb $B E$ and $H A V E$. $(11 \mathrm{a}, \mathrm{b})$ partly show the feature syntheses or analyses, to make or to analyze the forms of is and are. $(11 \mathrm{c}, \mathrm{d})$ shows the other cases.

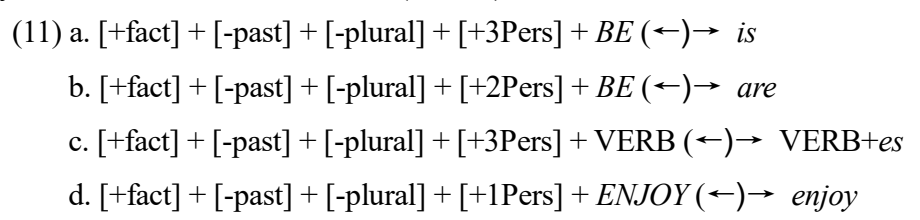

Redundancy rule might be proposed to catch the generalization that holds in the other cases. However, the formal invariance does not guarantee the non-occurrence of the feature. In (11d), the verb enjoy in the given context does not show conjugated forms. But this does not mean that the verb in question does not have conjugation.

Though mood, tense, number, person categories among CLE may not be formally marked, S-Aux, perfect, W-Aux are phonetically expressed without exception. Neg beneath the S-Aux indicates the lexical elements such as not, never, etc. Neg has another node under W-Aux, which occupies the position after the first element of W-Aux, for example be not going to, have not to, etc.

Number category has the feature $[ \pm$ plural $]$ and person category has the feature $[+1$ Pers $]$, [+2Pers] and [+3Pers]. Perfect category has the feature [+have -en] which is not derived from the lexical information. For us, these categories are used in general with positive feature. But negative features may be useful for the description of the related forms. For example, the feature [-1Pers] can be used for encompassing [+2Pers] and [+3Pers]. The W-Aux comprises the weak-auxiliaries like do, [be able to], [have to], and progressive [be-ing] which cannot be derived from the lexical information. The reason why perfect is not included in W-Aux category is that the concatenation of perfect and progressive like have been -ing is possible. On the other hand, the passive verbs are postulated in lexicon as such, for example, $B E$ MOVED: $[\mathrm{NKP}, \ldots, \mathrm{PP}(\mathrm{P}=b y)]$, in which BE MOVED can be treated as a passive verb. ${ }^{(1)}$

\subsubsection{Sentence-subject and VP-subject}

As suggested in 2.2.1, English sentence has to do with two subjects: one is S-subject (sentence-subject), the other VP-subject. What is important in S-subject is its position. Other things being equal, in declarative sentences, the two subjects are not distinct in the

\footnotetext{
(1) By this, it can be clearly indicated which verb can be passivized. The more is that the peculiarities of arguments would be represented in the argument structure of the lexicon. Semantic features peculiar to passive verb can also be described in the lexicon. Contrary to this, if adopted passive transformation, lexical traits relative to passive verb would not be described in the lexicon.
} 


\section{Restructuring and the Proper Syntactic Analysis}

majority of cases. This is similar to VP-internal subject in Chomsky (1993), etc., ${ }^{(1)}$ or to $v$ P-internal subject in Chomsky (1995), but not the same.

According to Chomsky (1995), the $v$ P-internal subject 'moves' to the Spec of TP (Tense Phrase), leaving the trace (Lee, 2002), but we do not take that line of thinking.

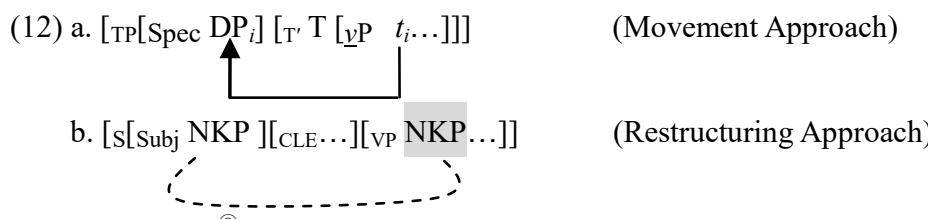

In (12a), the $\mathrm{DP}^{2}$ moves from the subject position of $v \mathrm{P}$ to the Spec position of TP. But in simplified (12b), there is no such movement. Even though the S-subject NKP and the VP-subject NKP are the same in form, the relations between them are complicatedly interrelated. Let's sum up the differences between (12a) and (12b) like the following.

(13) a. Movement is necessarily required in (12a), but not in (12b).

b. The movement leaves trace in (12a), but not in (12b). In (12b), if S-subject shows up, the NKP in VP-subject comes to be under shadow treated as 'non-existent'.

c. In (12a), movement is restricted to DP in (12a), but in (12b) S-subject is not restricted to NKP. The S-subject position can be filled with PP, Wh-phrase in direct question, ${ }^{3}$ and the expletive there, etc. The dotted line in (12b) symbolizes this somewhat loose relation.

d. In (12a), the movement is mechanical in nature, which seems to play no role in semantics whereas in (12b) the constituent that occupies S-subject position could play a decisive role to provide functional account to VP-subject.

Most importantly, in (12a), the S-subject is belonging to TP, but not in (12b). In general, the subject is a major constituent of a sentence. It can be isolated independently, dropped comparatively freely, and transported more or less freely to another position. Since a sentence can have Extra-sentential constituents like topic phrase, presentational phrase, vocative phrase, etc., the subject can be related with these extra-sentential constituents. Therefore, it is enough to say that tense is not intrinsically related to subject. And, basically $\mathrm{X}$-Bar convention is dubious at its justification and applicability. It is nothing but an arbitrary convention without serious empirical supports.

For us, the CLEs do not have Spec position. If they all have Spec positions, then a lot of Spec positions can be generated or postulated to be exploited without constraints and

\footnotetext{
(1) After Kitagawa (1986), Speas (1986), etc. there are many other proposals concerning VP-Internal Subject Hypothesis in addition to Chomsky (1993).

(2) After Abney (1987), it is trendy to use DP (Definite Phrase) instead of NP, but we do not accept DP hypothesis. DP hypothesis seriously distorts the concept of the head of nominal constructions.

(3) Instead of $\mathrm{C}$, we posit $\mathrm{R}$ position in front of a clause. Subordinate conjunction like that, whether (or not), relational connector like because, since, though, etc., Wh-phrase of indirect interrogative and Ex-phrase of exclamative sentence are assumed to be posited in $\mathrm{R}$ position.
} 
evidences. Moreover in (12a), a rigorous necessary relation should be held between the moved DP and the trace. In (12a), between the moved DP and the trace intervenes only tense or agreement, different from those in (12b). In (12b), tense is but a category among CLEs, which consist of mood, tense, S-Aux, Neg, Num, Pers, Perf, W-Aux, etc. categories.

In movement approach, the subject case is assigned to the moved DP by tense. But tense has nothing to do with subject case, because tense is a property that a proposition can have, to be settled at a certain point of time. For us, the nominative case is lexically related with a verbal element, given in the lexicon like in (6a, bi-ii) above. The arguments in TG are known to have only $\theta$-roles.

(12b) shows the restructuring approach. Other things being equal, the VP-subject tends to become an S-subject. This might be due to the fact that S-structure is conceptually analogous to VP structure, so far as NKP argument is concerned. This relation works as Subject Precedence Principle, in the sense that, other things being equal, the S-subject position exclusively selects VP-subject.

The constituent John in the S-subject and John in VP-subject are related by restructuring. John in S-subject is treated as 'existent', whereas John in VP-subject is treated as 'non-existent', thus under shadow. Now consider the following.

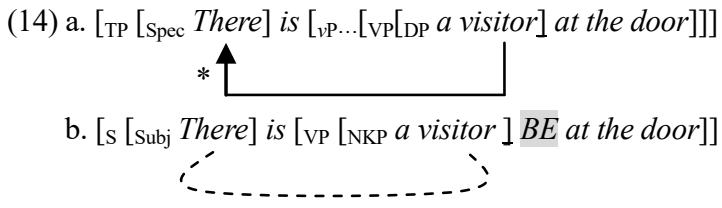

(14a) shows movement approach, and (14b) restructuring one. In (14a), the DP cannot move to the Spec of TP, simply because the position is already filled with there. Movement approach to Spec of TP cannot but to fail. ${ }^{\circledR}$ We don't know how the VP-Internal Subject hypothesis could get through this difficulty. One of the proposals might introduce LF-adjunction of the associate to there in Spec position. Later applies the operation like LF deletion to the expletive there. However, this is untenable, because the expletive there is very important to semantic interpretations of the very construction (cf. 3.3).

On the other hand, the argument structure in (14b) is preserved intact, and the expletive there and the VP-subject NKP a visitor is related by restructuring: a visitor in the S-subject position is deprived of its privileged position by expletive there, and VP-subject $a$ visitor returns to its original place, resulting in Subject-Verb inversion. The $B E$ verb is restructured with CLEs to make the conjugated verb is. For detailed discussions see the next section. It is expected that Two-Subject Hypothesis provides critical means to reach explanatory power to the problems not yet touched upon.

(1) See Chomsky's research on LF-move, LF-adjunction, case feature checking, etc. (Choe, 2008:94-5) 


\section{Restructuring and the Proper Syntactic Analysis}

It is specially noted that there are separately introduced subjects as in the infinitive clause and the gerund constructions. Consider the following.

(15) a. For John to [ t give Mary a gift] is a big event.

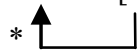

b. For John $\left[\mathrm{FP}[\mathrm{F}\right.$ to $]\left[\mathrm{VP}[\mathrm{NKP}\right.$ John $]\left[\mathrm{vP}^{-1}\right.$ give Mary a gift] $]$ is a big event.

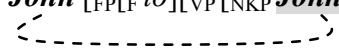

In (15a), we postulate a fictitious movement applied to the infinitive construction, but the movement is not allowed to account for the proper formulation of the structure. It is because there is no reason for the VP-subject to move to the S-subject position of the infinitive to construction. The infinitive to cannot assign subjective case to John. It is the preposition for to assign accusative case to John. We don't think that the Chomskyan approach effectively provides enough account as to how the constituent for John or John in (15a) can be analyzed as subject.

In (15b), John of PP For John is qualified as extra-sentential subject, and the infinitive to takes the role of functional element, to get syntactic function by eliminating VP subject. Here, we postulate functional category $\mathrm{F}$ to accommodate the infinitival functional element to, the gerundive functional element -ing, and participial functional element -ing. After these functional elements, there follows VP regularly lack of VP-subject. The dropping of VP-subject has no exception. In this case, it is not wise to abandon VP argument structure accommodating VP-subject, because VP argument structure with NKP is a very useful and convenient device to accommodate all kinds of information about lexical item. For the preservation of the argument structure, let's propose a separate system of category branching, like $\mathrm{FP} \rightarrow \mathrm{F}+\mathrm{VP}, \mathrm{VP} \rightarrow \mathrm{NKP}+\mathrm{VP}^{-1}, \mathrm{~F} \rightarrow$ to (infinitival), -ing (gerundive), -ing (participial). Here $\mathrm{VP}^{-1}$ indicates VP category lack of VP-subject, i.e., lack of NKP subject. (15b) basically reflects such analyses as proposed above. Here we assume that there is a restructuring relation between VP-subject John and the object in PP of (15b).

\section{ET construction and restructuring}

\subsection{There be construction and restructuring}

As is well known, the approaches to the ET construction usually have a tendency to involve very elusive processes to be understood. Even the highly respectful grammarians have no answer to the question of what the subject of the ET construction is. Is it the ET, or the 'notional subject' (Quirk et al., 1985)? Let's see Chomsky's approach like the following.

(16) a. There is a man in the garden.

[+Nom] [ $\theta$-role]

b. Is there a man in the garden?

c. CHAIN (there $e_{\mathrm{i}}$, a $\left.m a n_{\mathrm{i}}\right) \quad$ (cf. Chomsky, 1995; Choe, 2008) 
In (16a), there is annotated by [+nominative case] and a man by [ $\theta$-role] in Chomsky (1995), etc. (16b) shows the there-be inversion at the interrogative of (16a). (16c) shows Chomsky's (1995) approach to (16a), which postulates a CHAIN consisting of the ET and the associate $a$ man.

The most serious problem with this approach is that the ET is treated as a true or complete NP. Rather, the associate is treated as if an appendix. However, this is questionable at least, because it is evident that the ET cannot designate anything. To designate something, either concrete or abstract, is the typical nature of nominal expressions. But the ET is not so.

(17) a. There's/There are some people in the waiting room. (Quirk et al., 1985:1405)

b. For there to be a success, we need to struggle.

c. I expected there to be a simpler solution.

d. There seems/seem to be employees who are dissatisfied with their transfers.

(17a) shows an example that although the notional subject 'people' is plural in number, the verb of there be may represent singular form. In this case, there is recognized as carrying number. In (17b), there is used as object of preposition for. In (17c), there is used as object of the verb expect. As to the quiz like (17d), there are two answers. The expressions of there seem and there seems both are received as alright. Another response is that only there seem is right (Sobin, 1997). ${ }^{(1)}$ From these exceptional usages, we cannot arrive at the conclusion that there is a full nominal. In practice, we cannot use the expression like *We want there, ${ }^{*}$ John designates there, etc.

With regard to (17a), Quirk et al. (1985) annotate that there's form is used in informal speech. This implies that in formal speech, it is not so common to use singular form. In $(17 \mathrm{~b}, \mathrm{c})$, there is used in a position to fulfill special function of expletive (cf. 3.3). Doubtless, there is not a typical nominal, but partly has nominal character. Where does this strange nature come from? For us, restructuring latent is the source of strangeness and ambiguousness. Let's see the following. ${ }^{2}$

$$
\begin{aligned}
& \text { (18) a. [s[ADv There][S[Subj [NKP } a \text { visitor]] [CLE } \cdots i s] \text { [vp [NKP } a \text { visitor] BE [ADv there]]]] }
\end{aligned}
$$

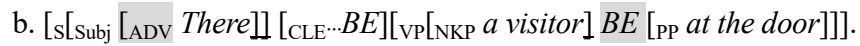

$$
\begin{aligned}
& \text { c. [S[Subj [ADV There]] [CLE is][Vp[NKP a visitor] } B E \text { [pP at the door]]]. }
\end{aligned}
$$

There in (18a) is a locative adverbial. $A$ visitor under $\mathrm{S}$ is $\mathrm{S}$-subject, and [NKP a visitor] under VP is VP-subject, as expected from (9) and (14b) above. The VP-subject [NKP a visitor] is under shadow, tentatively not to be seen from outside. The verb $B E$ is restructured into CLE for the composition of the real verb. (18a) has nothing special as a sentence with

\footnotetext{
(1) Sobin (1997) presents a lot of irregular forms that appear in the agreement relations between subject NPs and the predicates.

(2) The examples of (18a-c) show rough syntactic structures. The elements contained in CLE at least are TP, NumP, and PersP. The CLEs in (18a-c) represent the simplified CLEs.
} 


\section{Restructuring and the Proper Syntactic Analysis}

adverbial there at the sentence-initial position. This can be called Adverb There Construction. ${ }^{(1)}$ But in (18b), the adverbial there is restructured into subject, occupying the S-subject position, excluding VP-subject from S-subject, i.e. depriving the favorite position of VP-subject. Instead, the VP-subject [NKP $a$ visitor] in situ vacuously returns to its own position, and emerges as a real subject. ${ }^{2}$ As a result, the Subject-Verb (Aux) inversion takes place. The Subject-Verb (Aux) inversion is typical indication of there to be in S-subject position. If not, Subject-Verb (Aux) inversion does not occur.

(18c) shows the result of restructuring. Here the feature compositions of CLEs and the verb $B E$ yields the form is. The restructured subject there is nearly bleached in meaning, so that it is not obvious that there is any trace of adverbial meaning. However, some trace might be perceived in the usage of there. ${ }^{3}$

The argument structures relative to the copulative ${ }^{\oplus} B E$ can be shown in the following.

(19) a. The argument structure of existential $B E$ : [there, _, NKP, PP]

b. The argument structure of copular $B E$ : $[\mathrm{NKP}, \ldots, \mathrm{NKP}]^{(5)}$

c. The argument structure of locational $B E:[\mathrm{NKP}$, , $\mathrm{PP} / \mathrm{ADV}]$

d. The argument structure of descriptive $B E$ : $[\mathrm{NKP}$, , AP]

In (19a), the ET is directly given in the lexicon. This gives an answer to the question why the pronoun it is not used in the expletive construction in English. It is because there is given as an expletive element in the lexicon. The real subject of (19a) is NKP following BE. (19b) shows the argument structure of copular $B E$. This $B E$ has two NKPs (Nominative Case Phrases): one is subject and the other is subject complement. In (19c), one NKP is subject, and PP or ADV expresses location. In (19d), NKP is subject and AP is adjective complement.

Progressive forms with the verb $B E$ are not included in (19). For us, the form of the progressive be -ing belongs to W-Aux. And, the passive forms with be -en are treated as

\footnotetext{
(1) This is sometimes called presentational there construction (Milsark, 1974; Choe, 1994) or presentative construction (Heath, 2018).

(2) Hazout (2004) sees that the expletive there is a subject and the real subject NP is a predicate. For us, there seizes S-subject position by restructuring, and thereby suppresses agent and/or participant role of the true subject.

(3) Bolinger's (1977:92-93) mention like 'there brings something into awareness, where 'bring into' is the contribution of the position of there and other locational adverbs, and 'awareness' is the contribution of there itself; specifically, awareness is the abstract location" suggests that the expletive there has some abstract meaning. The expression like '? There is a boy there.' seems awkward. However, the question like 'Is there anyone there?' seems alright. The information value of the former seems to be low.

(4) Here we use the term 'copular' narrowly to the $B E$ verb that calls for the structure [NKP, , NKP]. We use the term 'copulative' widely to encompass all the $B E$ verbs.

(5) As to the second NKP in this structure confer the appendix of Schütze (2001). The post-copular pronouns rarely occur nominative forms cross-linguistically. But we think that the post-copular accusative forms represent special usages. In Korean, there appear nominative case markers in the negative sentences of the copular sentences. In English, confer the examples like: I am I, She's she and He is he.
} 
passive verbs.

\subsection{Other expletive constructions and restructuring}

The expletive constructions are not restricted to there be construction. Other verbs such as seem, appear, occur, be likely to, and happen, etc. can make expletive constructions. Consider the following.

(20) a. There seems to be a visitor at the door. (cf. It seems that there is a visitor at the door.)

b. There is likely to be a visitor at the door. (cf. It is likely that .)

c. ${ }^{*}$ There seems there to be a visitor at the door.

As far as there be constructions are concerned, $(20 \mathrm{a}, \mathrm{b})$ are basically identical to $(18 \mathrm{~b}, \mathrm{c})$. In addition to there be, $(20 \mathrm{a}, \mathrm{b})$ have other elements like seem to and be likely to. These elements can be treated as 'non-existent', because these elements cannot be seen to have important information. This may be called Transparency Effect (TE). The examples of (20a, b) have 'transparent' parts in shadow. The predicates having TE effect in $(20 a, b)$ may be equivalent to the higher verbs of $(20 a, b)$. Excluding these parts from $(20 a, b)$, the residual parts would be identical to there be construction in $(18 \mathrm{~b}, \mathrm{c})$. (20c) is ill-formed, simply because 'seem (s) there to' is not equivalent to 'seem $(s)$ to'.

(21) a. There appears a visitor at the door.

b. [s [ADv There] [NKP a visitor] appears [vP [NKP a visitor] APPEAR there]]]

c. [s [Subj [ADV There]] appears [VP [NKP a visitor] at the door]]]

d. There occurs an accident in the street.

(21a) shows there appear construction. (21b) shows the structure having two subjects: one is S-subject $a$ visitor, the other is VP-subject $a$ visitor under shadow. (21b) is not the ET construction, because the [ADV there] in (21b) is an adverbial constituent. In (21c), [ADV there] deprives S-subject position, so the ET construction results. The same can be applied to there occur construction of (21d).

Now, let's see PP in S-subject position.

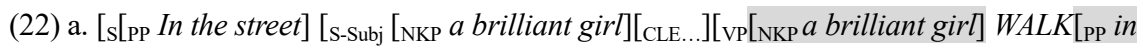
the street]]]

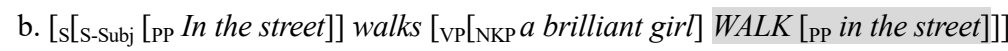

(22a) is a sentence with PP adverbial at the sentence-initial position. The VP-subject $a$ brilliant girl becomes S-subject, i.e., restructured into S-subject position. The sentence-initial PP in the street originally posited in VP. The VP structure preserves its argument structure. The shadowy VP-subject is restructured into S-subject position. In this case, Subject-Verb inversion does not occur as shown in (22a).

Different from this, in (22b) the PP in the street appears in the S-subject position, depriving the exclusive position of VP-subject. This accompanies Subject-Verb (Aux) inversion. The meaning of this inversion is that there happens a very uncommon event. 


\section{Restructuring and the Proper Syntactic Analysis}

The seem-constructions or other approximate expletive construction similar to regular ET construction does not show the full range of syntactic variance.

(23) a. There does not seem to be a brilliant girl in the street.

b. "Does there seem to be a brilliant girl in the street?

c. "Who does there seem to be a brilliant girl in the street?

d. ?'Does there appear a brilliant girl in the street?

e. ${ }^{* *}$ Does [in the street] walk a brilliant girl?

(23a) shows negative sentence with the verb seem. (23b) shows Yes/No question with the verb seem. (23c) shows Wh-question with the verb seem. (23d) shows Yes/No question with the verb appear. (23e) shows the Yes/No question with PP in S-subject position. All are not well-formed.

The ill-formedness is more or less related to the modal expressions, and in general modals are apt to be considered taken for granted in a given situation. Modals are not so important. Thus, the facts taken for granted are hardly negated or questioned. If negated or questioned, modals become important.

\subsection{The functional approach to the ET constructions}

Despite lots of discussions about the nature of the ET construction, it could be said that the core of its function is not wholly uncovered. It has been widely assumed that the ET construction requires the unaccusative verbs (arrive, appeal, accumulate, burn, coexist, emerge, fall, freeze, hover, live, lurk, melt, predominate, swing, etc.), and it is also assumed that the unergative verbs (run, talk, resign, etc.) do not select the ET construction (Perlmutter, 1978; Levin, 1993; Deal, 2009). However, this division of the verb classes is more or less unstable and does not say anything about the motivation of the phenomena. It is necessary to consider the structural characteristics of the ET construction.

First of all, we must ask the question of why transitive verbs are not allowed in ET construction. For us, the answer is simple and straight. It is because the argument structures of the transitive verbs are not compatible with the ET construction. In ET construction, the expletive there takes the S-subject position that VP-subject exclusively takes by the Subject Precedence Principle. As a result, the subjects of the transitive verbs and unergative verbs are eliminated from the favorite S-subject position for fulfilling the role of agent or participant. ${ }^{(1)}$ Consider the following:

(24) a. * There likes John Mary.

b. like: [NKP, _, AKP]

c. ${ }^{\text {?* }}$ There talks a president at the meeting.

d. 'There walks a stranger in the desert.

\footnotetext{
(1) This $\theta$-role improvised here is concerned with the role of subject of the unergative verb.
} 


\section{Hong-Pin Im}

e. (i) 'There runs a car at the cliff. (ii) A car runs at the cliff.

(24a) has no room into which the two arguments of the verb like shown in (24b) are allocated. (24c) shows that the unergative verbs are not allowed to occur in the ET construction, too. It is because in (24c) the VP-subject a president, due to there being at S-subject position, must remain at its place in VP. The VP-subject position is not the favorite position for the NKP to fulfill the participant role. Thus, the unergative verb talk is barred to occur in the ET construction. Let's look at (24d, e). If the verbs walk and run belong to the unergative, and if the verbs are not compatible with the ET constructions, then (24d, e) should be ill-formed (Lee, 2012). However, they seem not so. There are meaning differences between (24ei) and (24eii). (24ei) seems to express a scene dangerous involving a car, whereas (24eii) seems to express performance of $a$ car.

Now, we state the principle of 'Subject Precedence Principle' like the following.

(25) Subject Precedence Principle (SPP)

VP-subject should occupy S-subject position to fulfill its proper function.

The ET construction does not concern with action or process itself. What is important in ET construction is the situation, not action or process. Action is only a part of situation. The alleged 'inactive' characteristics of the ET construction (Choe, 2008) is related to this structural meaning. When the VP-subject is suppressed to remain in the VP position, there emerge situational characteristics not directly involved in action. Now consider the following.

(26) a. Speaker A: Do you have a baby?

b. Speaker B: There plays a baby on the chair.

In (26b), the speaker B answers the question (26a) by suggesting a situation relative to his baby. (26b) does not concern about the will or the action of the baby, that is, (26b) is not the expression of the participant involved in action. (26b) only conveys information about the situation around his baby. This demonstrates important function of the ET construction: it only conveys situation. We present this like the following.

(27) The Semantic Function of ET construction

ET construction conveys information about the situation at issue.

In general, it is stressed that the ET sentence has an indefinite effect concerning the entity expressed by the 'true subject' (Choe, 2008; Chang, 2012). This is natural, because information is usually new in situation. However, the information is not always new. When the old entity is at issue, the definite article could be used even in ET sentences. ${ }^{(1)}$ The syntactically and/or semantically forced use of the definite article cannot escape from using. Some object(s) could also be emerged from the background, to introduce a new topic to be

\footnotetext{
(1) Many examples with definite article in its true subject in the ET construction are to be found in Bolinger (1977) and Lakoff (1987).
} 


\section{Restructuring and the Proper Syntactic Analysis}

talked about. ${ }^{(1)}$

Now, consider the following.

(28) a. On chair stood (i) a baby / (ii) John.

b. On chair (i) a baby / (ii) John stood.

c. (i) A baby / (ii) John stood on chair.

In (28a), the PP 'on chair' is on our S-subject position. This says that the PP on chair seizes the S-subject position that is of great importance for information. Thus (28ai) informs imminent and dangerous situation about a baby. The baby might fall from the chair. In (28aii), John is about to make a very important announcement on a critical situation. John might not fall from the chair, because he is not a baby, but his position or the situation around him is very unstable.

In (28b), on chair an adverbial does not seize our S-subject position, but takes the sentence-initial position. In this case, the sentence does not express imminent situation, but the event might be of special interest to the hearer. What is expressed in (28bi) is a somewhat prominent developmental stage of the baby, and that in (28bii) is something special event for John. (28c) shows regular structure concerning the adverbial. Nothing special is expressed in (28c): in (28ci) the event is natural or anticipated for the baby, and (28cii) the event is prepared or everyday work for John.

It is evident that various factors work in ET construction. The most important is that there works Two-Subject Hypothesis and the S-subject position plays a decisive role to demonstrate the role of agent and/or participant. Barring VP-subject to become S-subject by way of the expletive there makes prominent the situational meaning.

\section{Interrogative sentence and restructuring}

\subsection{Direct Wh-interrogative and restructuring}

In Chomsky (1977, 1981, 1995, 1999), the direct Wh-interrogatives are formed by movement of Wh-phrase to the Spec of $\mathrm{C}$ with feature [+Wh], as shown in the following.

$$
\begin{aligned}
& \text { (29) a. [CP[Spec Whom } \left.\left.]\left[\mathrm{C}^{+} \mathrm{Wh}\right]\right][\mathrm{IP} \text { do you [vp like t }]\right] \text { ? } \\
& \text { b. What do you think } \left.\left.\left[{ }_{\mathrm{CP}}\left[\mathrm{Spec}_{j} t_{j}\right]\left[\mathrm{C}^{+\mathrm{Wh}}\right]\right][\text { that }]\right] \text { John gives Mary } t_{i}\right] \text { ? }
\end{aligned}
$$

(29a) shows the typical movement of Wh-phrase whom. Whom moves out of $t$ marked position to Spec of $\mathrm{CP}$, attracted by $[+\mathrm{WH}]$ feature at the head of $\mathrm{CP}$. The movement left trace $t$. The Wh-phrase whom in (29a) can appear with the nominative form who. The case alternation as expressed in whom/who cannot be accounted for by the movement like (29a).

\footnotetext{
(1) Chung (2009) deals with discourse function of the ET construction.
} 
(29b) shows a long distance Wh-movement. The Wh-word what moves out of the embedded object position, attracted by the inherited $[+\mathrm{WH}]$ feature at the Spec of the embedded $\mathrm{CP}$, leaving the trace $t_{i}$, and then in turn moves out of the Spec of embedded CP attracted by matrix $[+\mathrm{WH}]$ feature, leaving the trace $t_{j}$, and then arrives at the Spec of matrix CP by Comp-to-Comp fashion of movement.

Since in (29b) the Wh-word what does not belong to the matrix sentence, it must be the case that the Wh-word comes from the embedded sentence. From this consideration, there seems inescapable to set up movement transformation in the long distance Wh-question.

What about the direct Wh-interrogatives in restructuring approach? Consider the following.

(30) a. [s[subj [AKP $\left.\left.\boldsymbol{W h o m}_{i}\right]\right]$ do [vP you like [AKP $\left.\left.\left.\boldsymbol{w h o m}_{i}\right]\right]\right]$ ?

b. [s[Subj [NKP [AKP $\left.\left.\left.\boldsymbol{W h o}_{i}\right]\right]\right]$ do you like $\left.\left[{ }_{\mathrm{AKP}} \boldsymbol{w h o m}_{i}\right]\right]$ ?

In (30a), the Wh-phrase whom occupies the S-subject position, just under S node. Since the category of the position is subject, the AKP object whom is to be restructured into S-subject. Whom in the VP comes to be under shadow, because it is treated as 'non-existent'. What about the Subject-Aux inversion? Since W-Aux (Weak-Aux) do is postulated in front of VP, Subject-Aux inversion applies vacuously. In (30b), whom may become who. Whom is restructured to NKP form, by appearing in the position of S-subject.

What about the long distance movement of Wh-phrase?

(31) a. What do you think that John gives Mary what?

b. [[ ${ }_{\mathrm{NP}}$ What $]$ did you say that you thought that it was likely that you would do what]? (Radford, 1988: 570)

c. "What did John complain that he had to do this morning? (Chomsky, 1977:85)

d. *What did John quip that Mary wore? (Chomsky, 1977: 85)

(32) a. Who bought what? (Norvin, 1999; Kim, 2008:23-24)

b. *What did who buy?

c. "What might he ask whether I hid__? (Radford, 1981:234-235)

d. *What would [for me to do __ annoy you? (Radford, 1981:233)

As to the examples like (31c, d), Chomsky (1977) says that it is unclear what property of the matrix VP permits it to be a 'bridge' (in the sense of Erteschik-Shir, 1973). But for us, it is clear what is the crucial factor operating in (31a-d). In (31a, b), the shadowy parts 'you think that' and 'you say that you thought that it was likely that' is not so important for communication that they can be treated as 'non-existent'. It is because the addressee you can be taken for granted in the discourse situation, the verbs say, think, believe, etc. also are given for granted in the question-answer discourse between addresser and addressee. The point is that these elements can be treated as 'non-existent'. Excluding these elements, the long distant Wh-question can be treated as a simple Wh-sentence. Some adjustments are needed to 


\section{Restructuring and the Proper Syntactic Analysis}

make the rest a good simple Wh-sentence. ${ }^{(1)}$

Contrary to these, the underlined predicates of $(31 \mathrm{c}, \mathrm{d})$ are 'heavy' or 'not transparent', so cannot be treated as 'not-existent', thus resulting in ungrammaticality. They cannot make simple Wh-interrogatives.

Different from (32a), (32b) is not well-formed. For this, Norvin (1999) proposed the principle of the 'shortest move'. But, for us, notwithstanding the VP subject who is the best candidate for the S-subject position, (32b) violates the principle of SPP, and thus becomes ill-formed. For Chomsky (1977), etc., (32c, d) are the examples explained by movement constraints. But for us, $(32 \mathrm{c}, \mathrm{d})$ can be accounted for by Transparency Effect (TE) of the matrix predicates. In $(32 \mathrm{c}, \mathrm{d})$, the contents of the matrix clauses are heavy, thus cannot be treated as 'non-existent'.

\subsection{Indirect question and restructuring}

Indirect questions are roughly the sentences in which Wh-phrases are in the embedded clauses. Let's look at typical cases.

(33) a. I wonder who bought it.

b. I wonder $\left[\mathrm{CP}_{\mathrm{CP}}\left[\mathrm{Spec} \boldsymbol{w h o ~}_{i}\right][\mathrm{C}+\mathrm{WH}]\left[\mathrm{IP} t_{i}\right.\right.$ bought it $\left.]\right]$.

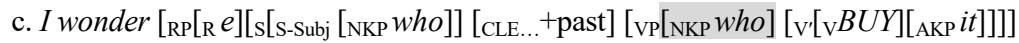

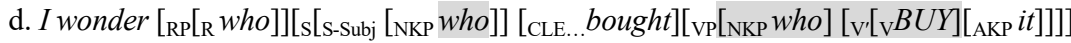

According to Chomsky (1981), etc., the matrix verb wonder in $(33 \mathrm{a}, \mathrm{b})$ takes $[+\mathrm{Wh}] \mathrm{C}$, which attracts the Wh-phrase who in the embedded clause to the Spec of CP. We can see this process in (33b). (33c) shows our analysis. We see that in (33c) the subordinate conjunct $R$ (Relational Connector) itself is $e$ (empty category). Consider the structure of the sentence like 'because he bought it'. We consider this adverbial reason clause should be analyzed as ${ }_{\mathrm{RP}}[\mathrm{R}$ because][s he bought it]]. In (33c), the VP-subject [NKP who] is restructured into the S-subject position according to SPP. And, since R position is empty, the S-subject who is restructured into the empty R position as (33d) shows. This is the reason why Subject-Verb inversion does not take place in (33d).

Now consider the following.

(34) a. I wonder who bought what.

b. ${ }^{*}$ I wonder what who bought.

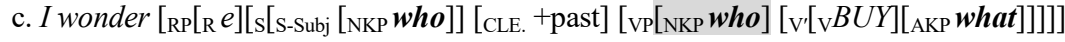

d. ${ }^{*}$ I wonder $\left[{ }_{\mathrm{RP}}[\mathrm{R} \boldsymbol{w} \boldsymbol{h} \boldsymbol{a t}][\mathrm{S}[\mathrm{S}-\mathrm{Subj}[\mathrm{NKP} \boldsymbol{w h o}]]\right.$ [CLE. + past] [VP[NKP $\left.\left.\boldsymbol{w h o}]\left[{ }_{\mathrm{V}}\left[{ }_{\mathrm{V}} B U Y\right][\mathrm{AKP} \boldsymbol{w h} \boldsymbol{a t}]\right]\right]\right]$

(34a) is well-formed, whereas (34b) is ill-formed. (34c) shows the internal structure of indirect interrogative. That (34a) is well-formed tells us that in (34c) S-subject [NKP who] restructured from VP-subject has the priority to select empty R position over other

\footnotetext{
(1) This Aux is under shadow, evading Aux doubling.
} 


\section{Hong-Pin Im}

Wh-arguments. It can be said that the Wh-subject has priority to select S-subject position. We assume SPP applies here too. From this, (34c) satisfies SPP.

On the contrary, (34d) shows the ill-formed structure of (34b), where VP-object what takes empty R position. It is noted that $[\mathrm{NKP} w h o]$ is in the S-subject position. This configuration violates SPP, and thus results in ill-formed sentence.

Interrogative sentences most distinctively reveals its sentence type by the formal traits. But the same form does not always convey the same function, e. g. the constituent who are you in the quotation " 'Who are you' is a Wh-question." is not a direct Wh-question. Therefore, it is necessary to set up performative analysis like the following.

(35) a. Addresser asks addressee a question "Who are you?" with the intention to get the answer from addressee.

b. Addresser states that he/she raises a question "I wonder who you are." with the intention to get some information from addressee.

(35a) presents performative analysis about the direct question like 'Who are you?' and (35b) about the indirect question like 'I wonder who you are.'. Indirect question as well as direct question contains the performative structures that reflect semantic and pragmatic aspects of meaning.

\subsection{Yes/No question and restructuring}

The noticeable trait of Yes/No question is that it does not have Wh-phrase in sentence-initial position. On the contrary, indirect Yes/No question accompanies Wh-phrase whether or not / if in the embedded question.

(36) a. Is Mary a brilliant girl?

b. I wonder $\left[_{R}\right.$ whether or not / if] Mary is a brilliant girl.

c. ${ }^{*}$ I wonder $\left[_{R}\right.$ e] Mary is a brilliant girl.

d. Whether or not / If Is Mary a brilliant girl?

(36a) is a direct Yes/No question, and (36b) is an indirect Yes/No question. (36b) is an example of indirect Yes/No question accompanying subordinate conjunctions whether (or not) or if. Without these Wh-phrases, (36b) becomes (36c), which is ungrammatical. Like (36b), the Wh-phrase should take place in R position. If not, Subject-Verb inversion should occur. (36c) shows that the empty category $\left.{ }_{\mathrm{R}} e\right]$ should be filled with Wh-phrase like (36b).

If then, why should the indirect Yes/No interrogatives have the subordinate conjunction, different from other Wh-interrogatives? We assume that restructuring is applied like (36d). Originally, the indirect Yes/No question is thought to have the subordinate conjunction whether (or not) or if in its sentence-initial position but under the shadow. When the Yes/No question is embedded, the Wh-phrase whether (or not) or if comes to show up in the $\mathrm{R}$ position. It is well accounted for the Subject-Verb inversion in (36d), because the Wh-phrase deprives S-subject position of Mary. 


\section{Restructuring and the Proper Syntactic Analysis}

The Old English syntax gives another support for (35b) hypothesis. According to Fischer et al. (2014:84), "In Old English, hwcefer ('whether') could be used in simple interrogative clauses followed by normal, that is, non-inverted, word order." If our (36d) is supported by the historical facts, our assumption about direct/indirect Yes/No question would be more convincing.

\section{Exclamative sentence and restructuring}

Let's compare the exclamative sentence with Wh-interrogatives.

(37) a. What a nice gift John gave to Mary!

b. "What a nice gift did John give to Mary?

c. (i) In what a good house John live! (ii) What a good house John live in! (d'Avis, 2016)

d. In what house does John live?

(37a) shows an exclamative sentence which takes Ex-phrase ${ }^{(1)}$ what (a) part. In this case, Subject-Verb inversion does not take place. On the contrary, (37b) is unacceptable as a direct question with what (a) part (Grimshaw, 1979; d'Avis, 2016).

Different from interrogative sentence (37d), the exclamative sentence (37ci) is not well-formed. This is because the preposition in (37ci) is not stranded (d'Avis, 2016), whereas (37cii) is well-formed because the preposition stranding does occur, contrary to (37d). This seems to support the correspondence approach, which assumes that exclamative sentences are not derived from other sources (Altmann, 1987; Michaelis, 2001; etc.). On the contrary, the derivational approach assumes that exclamative sentences are derived from other sources (Fries, 1988; d'Avis, 2016).

For us, restructuring applies to an exclamative sentence in the following way.

(38) a. ${ }_{\mathrm{RP}}\left[{ }_{\mathrm{R}}\right.$ What a nice gift $]\left[\mathrm{S}[\mathrm{Subj}[\mathrm{NKP} J o h n]][\mathrm{CLE}\right.$ gives $]\left[\mathrm{VP}[\mathrm{NKP} J o h n]\left[\mathrm{v}^{\prime \prime}[\mathrm{V} \cdot[\mathrm{V}\right.\right.$ GIVE] $[\mathrm{AKP}$ a very nice gift]][pp to Mary]]]]]

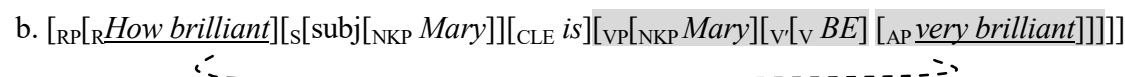

We assume that in (38a), the Ex-phrase 'what (a) NP' takes place in the R position. Likewise, we assume that in (38b), the Ex-phrase 'how brilliant' takes place in the $\mathrm{R}$ position. Here $\mathrm{R}$ is the category for introducing the relational connector like because, since, though, although, etc. as in the indirect Wh-interrogatives.

We do not postulate movement in the formation of the exclamative sentence. (38b) shows how the Ex-phrase is related to AP. Regarding (38a), the same relation can be postulated. The Ex-phrases and VP-internal constituents in question in $(38 \mathrm{a}, \mathrm{b})$ are related

\footnotetext{
(1) This indicates Exclamatory Phrase (Ex-phrase), similar to Wh-Phrase. But this does not imply that the function of Ex-phrase is approximate to Wh-phrase.
} 
to each other by restructuring. The dotted line connecting the two constituents in (38b) indicates this relation.

Then how can be accounted for the structure like (38a, b)? As you see, the VP structures in (38a, b) are satisfied with the argument structures like (6bii) for (38a) and the argument structure like (19d) [NKP $B E \mathrm{AP}]$ for the adjective sentence (38b). The verb give with AKP $a$ nice gift makes $\mathrm{V}^{\prime}$, and $\mathrm{V}^{\prime}$ with PP to Mary makes $\mathrm{V}^{\prime \prime}$, and $\mathrm{V}^{\prime \prime}$ with NKP John makes $\mathrm{V}^{\prime \prime \prime}(=\mathrm{VP})$ according to the principle of Hypothesis of Variable Medial Projection. Then NKP John is restructured to S-subject. And, the Ex-phrase what a nice gift is set up in R position by restructuring which treats 'non-existent' as 'existent'. And, the verb GIVE with the CLEs makes the real verb gives. In (38b), the similar processes to (38a) proceed.

In (38a, b), the S-subjects are occupied by VP-subject, therefore Subject-Verb inversion does not take place. This is due to the assumption that Ex-phrases in question are posited in R, not depriving the $\mathrm{S}$-subject position in $\mathrm{S}$ (Sentence).

Here, it should be noted that the exclamative sentence does not have indirect exclamative sentence. Look at the following.

(39) a. How elegant she is! (Exclamative Sentence)

b. My neighbor wonders how elegant she is. (Indirect Interrogative)

c. My neighbor admires "How elegant she is."

In $(39 a, b)$, the two underlined parts are exactly the same. At this, one might wonder whether or not the origin of the exclamative sentence could be the indirect question. Even though the form and the meaning of the exclamative and the indirect interrogative are similar to each other, we do not agree to the Derivational Approach, which claims that the exclamative sentence comes from other sources. Here we examine the similarity between the exclamative sentence and the indirect interrogative. Let's consider the following.

(40) a. I wonder $\left[\mathrm{RP}_{\mathrm{R}}\right.$ (i) what gift, (ii) ? what nice gift, (iii) ${ }^{*}$ what a nice gift $][\mathrm{s}$ John gave to Mary $\left.]\right]$.

b. [I admire it/I am surprised at that $]$ "[ ${ }_{\mathrm{RP}}\left[_{\mathrm{R}}\right.$ what a nice gift $][\mathrm{S}$ John gave to Mary $\left.]\right]$ ".

c. Addresser admires "How brilliant Mary is."

d. " [What a nice gif $]_{i}$ do you think $t_{i}$ John gives $t_{i}$ to Mary.

First, the indirect question of (40a) has the matrix sentence. But in (40b), the exclamative sentence does not have the matrix sentence. (40b) shows direct quotation of the exclamative sentence, not grammatically embedded in the matrix sentence. The shadowy part in (40b) might be the emotional circumstances around the exclamative sentence. This can be extended to the performative analysis like (40c).

Second, (40d) shows that the so-called Long Distance Movement (LDM) of Ex-phrase does not take place. This is relative to the fact that Ex-phrase cannot be embedded. LDM can be characterized as movement from embedded clause to the higher clause. Indirect interrogative sentence shows similar phenomenon in that there is no such movement like (4d). 


\section{Restructuring and the Proper Syntactic Analysis}

But if the movement like (40d) is possible, the result cannot be an indirect question, because Wh-phrase should be in the sentence-initial position. The exclamative sentence and the indirect question show different internal structures, despite the identical surface structures.

Third, it should be emphasized that Wh-phrases except 'what (a) Noun' or 'how Adjective' cannot be used as Ex-phrase of exclamative sentences. This is different from the indirect question (d'Avis, 2016). For example, the question like "For whom the bell tolls?" cannot be an exclamative sentence.

Fourth, the distinction between the exclamative and the indirect interrogative is explicitly discriminated in terms of grammatical forms and constructions. For example, in Korean, the exclamative sentences are formed by characteristic exclamatory final endings like -guna, -gun, etc. which are different from indirect interrogative endings like -nji, -nga, etc. Though it can be agreed that the interrogative sentences sometimes are used to express emotional meaning, the sentences in question cannot be characterized as exclamative sentences. It is because the indirect interrogative sentence can be embedded in the matrix sentence, different from the exclamative sentence.

These pieces of evidence can be seen to support the Correspondence Approach which sees that the exclamative sentences are not derived from other sources.

\section{Imperative sentence and restructuring}

\subsection{Imperative and the base form of verb}

As is well known, imperative sentences are in general formed with action verbs, and that not accompanying the subject. The verbs in the imperative sentences hardly carry CLEs like mood, tense, S-AUX, person, number, and W-Aux elements, etc. The imperative does not accompany passive forms and the positive progressive forms. Imperative verbs are characterized as the base form of the verb. In practice, the copular imperative at surface genuinely consists of the base form of the copular, like Be diligent. Generally, imperative sentences are not compatible with modal expressions.

Let's present this like the followings.

(41) Constraints of Imperative Sentences

a. Imperative Sentences are not compatible with S-Aux and/or W-Aux.

b. Imperative Sentences are not compatible with modal expressions.

This can be thought to give account for the source of the imperative force. We assume that the basic form of imperative sentence can be set up like (42b).

(42) a. Come here!

b. I order you to come here. $\rightarrow$ Come here!

c. You, I order you to come here. $\rightarrow$ You, come here! 
d. Performative Analysis: Addresser requests addressee ${ }^{(1)}$ to come here.

e. Do come here! (Quirk et al., 1985).

f. (i) I order you to come here. $\rightarrow$ (ii) Come here! $\rightarrow$ (iii) Do come here!

If we apply restructuring analysis to (42a), 'I order you to' part of (42b) comes to be under shadow. Though the shadowy part is 'non-existent', it is treated as 'existent', not seen or heard from/to outside. (42c) is similar to (42b), but subject-like constituent you is used. Examined in (42c), this constituent might be seen as a vocative NP or presentational NP relative to addressee in the performative analysis. (43c) shows that the origin of imperative force comes from the performative verb like order, request, command, etc. just as postulated in (42b-d).

(42e) is of special interest to us. It is pointed out that the positive imperative can be made more persuasive or insistent by adding $d o$ in front of the imperative verb (Quirk et al., 1985). In this case, the problem is what the role of $d o$ is. If $d o$ is an Aux, then (42e) violates the constraint of (41a). (41a) says that imperative is not compatible with Aux. Or, if $d o$ is not an Aux, then it violates the basic principle of the verbal construction: pure verbs cannot be consecutively used without any intervening elements.

Here we assume that $d o$ in (42e) is W-Aux. Then the usage of $d o$ in (42e) is straightly accounted for. If $d o$ is an Aux, then the constraint of verb sequence cannot apply to (42e). The relevant structure can be thought to be that like (42fiii). If comparing the structure (42fiii) with other Aux constructions, it is pointed out that Aux cannot appear in the structure like (42fi). For the solution of this problem, we need a special assumption about the behavior of the Aux do. Do-insertion occurs in the later step, not in the original structure. As you see in (42f), Aux do is restructured (or inserted) into after the step (42fii). Consequently, the constraint (41a) can be evaded. Let's see the negative verbal imperative.

(43) a. (i) Go away. (ii) Do not go away.

b. (i) I order you not to go away. $\rightarrow$ (ii) ${ }^{*}$ Not go away. $\rightarrow$ (iii) Do not go away.

(43aii) is the negative counterpart of (43ai). In this, do is an Aux. If not, (43aii) violates constraint of verb sequence. If $d o$ is Aux, there is no such violation. (43bi) shows the origin of the imperatives. No Aux is in (43bi). (43bi) can be restructured into (43bii), by positing relevant elements under shadow as 'non-existent'. But (43bii) is not well-formed. Therefore, Aux $d o$ is restructured by inserting into the structure. Here too, we need a special assumption about the behavior of the Aux do. Do-insertion occurs in the later step, not in the original structure.

Since the Aux do is free from modal meaning, it can be thought to be exempt from the application of the constraints $(41 \mathrm{a}, \mathrm{b})$.

\footnotetext{
(1) Addresser and/or addressee may be plural.
} 


\section{Restructuring and the Proper Syntactic Analysis}

\subsection{Adjective imperative and restructuring}

Let's take some of Pollock's (1989) examples.

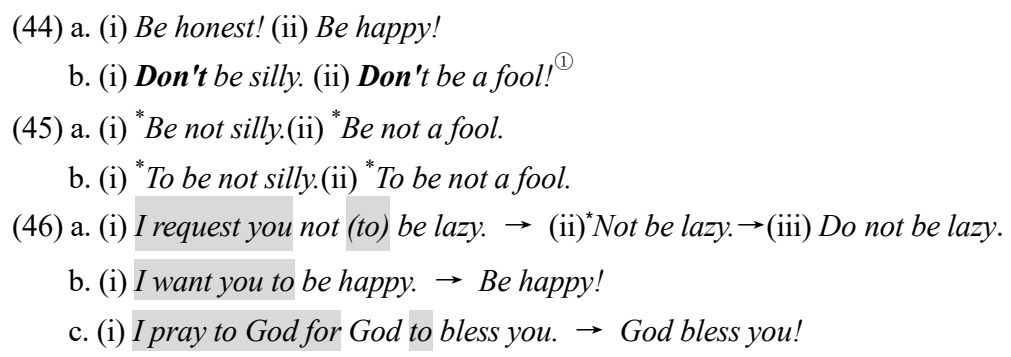

Different from the positive imperative, (44bi-ii) show that the negative imperative of the adjective like (be) honest or (be) happy makes use of do. On the contrary, (45a, b) show that the forms like be not and to be not are not permitted. (46ai) shows the origin of the negative imperative. After restructuring applied to (46i), there becomes (46aii) not be lazy, which is not well-formed. To save the structure, do-insertion is applied. Unexpectedly, the process is same as (43b), different from Pollock's (1989) claim.

In this case, the problem is why be not is not allowed. Pollock (1989) sees that the verb be and have goes over the barrier NegP (Negative Phrase). If Pollock's (1989) argument were on the right track, $(45 \mathrm{a}, \mathrm{b})$ should be well-formed, since in $(45 \mathrm{a}, \mathrm{b})$ the verb be goes over NegP by his putative movement. But $(45 \mathrm{a}, \mathrm{b})$ are ruled out.

(46ai) shows restructuring applied to the negative adjective imperative. The performative parts are under shadow. The result is (46aii), which is ill-formed. (46aiii) shows the structure where the Aux do is inserted to save the structure. Here too, we need a special assumption about the behavior of the Aux do. Do-insertion is carried out in the later step, not in the original construction. This is not different from the negative verbal imperative in (43b).

(46b) is a kind of the optative sentence. Or, it can be understood as a command to the change of state. Here the performative verb may be postulated as want, wish, hope, etc. (46c) is a regular optative sentence. Here the performative parts are under shadows.

It goes without saying that there is nothing special in the adjective imperative in English. It shows the same characteristics as other verb's imperative. Only special is the problem of how adjectives can be imperative. It can be said that the controllable state may be an object of the imperative. But the uncontrollable state is to be an object of wish or pray.

\section{Declarative sentence and restructuring}

As to the declarative sentence, we do not posit $\mathrm{C}$ position. We do not introduce the abstract

\footnotetext{
(1) In this, a fool is not an AP (Adjective Phrase), but an NP. Since the semantic behavior is similar to AP, Pollock (1989) treats it as if AP.
} 
feature like $[-\mathrm{WH}]$ to $\mathrm{C}$, to characterize the declarative. The order of arguments given in the lexicon is reflected in the structure.

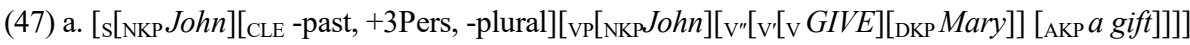

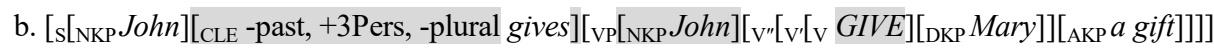

(47a) shows the base structure reflecting the information of argument structure in which the VP-subject [NKP $J o h n]$ is restructured into the S-subject position. (47b) is the result of the restructuring. The vp-subject is under shadow and the CLEs are realized as a morphological marker in the form of gives, and the CLEs also in shadow, since they are reflected in the form of verb. Naturally, the S-subject John precedes the verb gives. This order is the typical indication of the declarative sentence. Introducing topic, presentational phrase, vocative words, scrambling, specific constructions relative to emphasis, etc. affect the order of constituents.

The following presents examples of subject or subject with others under shadow. (Quirk et al., 1985: 896)

(48) a. I Beg your pardon.

b. I Don't know what to say.

c. It Looks like rain.

(48a-c), the shadowy parts are not expressed literally. At elliptical approach, the shadowy part should be supplemented or remedied with recourse to the discourse situation or considering linguistic contexts. But at restructuring approach, though in (48a-c) the shadowy parts are 'non-existent' externally, they can be treated as 'existent' at least in the linguistic and pragmatic context.

The declarative sentence can be characterized by the performative factors like in (49). Here the performative related parts are also under shadow, treated as 'non-existent'.

(49) Performative Analysis:

Addresser states to addressee "John gives Mary a gift."

We do not select 'say' verb for the declarative performative verb. The verb 'say' might implicate various sentence types. The verb 'state' is suitable for expressing the speaker's attitude towards proposition.

\section{Conclusion}

We have proposed some crucial ideas mainly about the proper syntactic analysis of English. We have introduced the concept of restructuring just like the one proposed in Im (2018a, b). In Im (2018), restructuring in a nutshell is conceived as the process to treat 'existent' as 'non-existent' or vice versa. What is emphasized in this is the identification of the sentence different from CP, Two-Subject Hypothesis and the VP structure.

We set up the argument structure for English ditransitive verb give like [NKP (Nominative 


\section{Restructuring and the Proper Syntactic Analysis}

Case Phrase), _, DKP (Dative Case Phrase), AKP (Accusative Case Phrase)], in which the syntactic arguments take its position and the case from the lexical information given in the lexicon. And here the underlined position is that of the verb. From this, as far as verbal arguments are concerned, the cases can be clearly defined. We make VP structure by projecting the lexical information to syntactic structure or tree. The NKP comes to be under VP. This is called VP-subject. Under the S, there comes another subject which is called S-subject. We arrive at Two-Subject Hypothesis.

Two-subject positions can be exploited to account for the subtle syntactic complexities, though in general the S-subject position is exclusively occupied by VP-subject. One of the advantages of the Two-Subject Hypothesis is that it fully explains the peculiarities of the ET construction. In this case, Subject-Verb (Aux) inversion occurs without exception. We could get fruitful results towards the function of Expletive There Construc -tions.

As to direct interrogative sentence, Wh-phrases are set up in S-subject position, and in this case, there occurs Subject-Verb (or Aux) inversion, except when the S-subject position is occupied by VP-subject. This means that Wh-questions are not formed by Wh-movement. For us, Wh-interrogative is given by the regular formation. If NKP occupies S-subject position, the order of constituents remains as given. In this case, VP-subject comes to be under shadow. But when the other constituent occupies the position of S-subject, Subject-Verb (or Aux) inversion occurs.

In the indirect question, Subject-Verb inversion does not occur. This is because Wh-phrase is assumed to occupy the $\mathrm{R}$ position, which is postulated for the subordinate clause containing the subordinate conjunction like because, since, though, after, before, etc.

As to the putative long distance Wh-movement, we take much of the role of the 'transparent' or 'weak' verb (or 'bridge verb'). By restructuring, they can be treated as 'non-existent', thus showing movement effect, which is not a real movement. In a lot of syntactic constructions, the restructuring approach is recommended.

Regular exclamative sentences in English are formed by the Ex-phrase, that is, the exclamatory phrase such as 'how Adjective' or 'what (a) NP'. The exclamative sentence behaves differently from interrogative sentence in Subject-Verb (or Aux) inversion or preposition stranding. And, Ex-phrases are restricted to 'how Adjective' and 'what (a) NP', whereas in the indirect interrogative, there is no such restriction. This means that though the exclamative shows similarities to the indirect interrogative, Derivationalist Approach cannot be maintained.

We assume that the Ex-phrase occupies R position here too, which is postulated for the indirect interrogative. By this assumption, we can account for the non-occurrence of Subject-Verb inversion in exclamative sentences.

As to imperative, we take much of the fact that the imperative verb does not carry any 


\section{Hong-Pin Im}

mood, S-Aux, person, number, W-Aux elements. Only one exception is related to $d o$ imperative. This implies that imperative verb is the infinitive form. From this, we can set up the underlying structure in which the infinitive to and the relevant structure requiring to infinitive are latent in front of the imperative verb. As to adjective imperative we also set up similar structures and processes. In negative imperative, the Aux $d o$ is inserted lately.

As to declarative, it is not easy to find out the crucial factors to distinguish typical traits of the declarative from other sentence types. In the majority, Subject Precedence Principle (SPP) in declarative is preserved, but in the expletive construction, SPP cannot be maintained. The critical factor of declarative force is considered to come from the performative verb.

With regard to little problems, we think we have proposed perspective solutions.

$\begin{array}{llll}\text { Abbreviations and symbols } & & \\ \Theta-\text {-roles } & \text { Theta-Role Signifying Semantic Role } & \text { P } & \text { Preposition } \\ \text { Agr }_{\text {S }} & \text { Subject Related Agreement } & \text { PerfP } & \text { Perfect Phrase } \\ \text { AK } & \text { Accusative Case Marker } & \text { Pers } & \text { Person } \\ \text { AKP } & \text { Accusative Case Phrase } & \text { PersP } & \text { Person Phrase } \\ \text { C } & \text { Complemantizer } & \text { PF } & \text { Prefinal Ending } \\ \text { CLE } & \text { Conjugation-Like Element } & \text { PP } & \text { Preposition Phrase } \\ \text { CP } & \text { Complemantizer Phrase } & \mathrm{Q} & \text { Question } \\ \text { DF } & \text { Declarative Final Ending } & \mathrm{R} & \text { Relational Connector } \\ \text { DK } & \text { Dative Case Marker } & \text { RP } & \text { Relational Phrase } \\ \text { DKP } & \text { Dative Case Phrase } & \text { S } & \text { Sentence } \\ \text { DP } & \text { Definite Phrase } & \text { S-Aux } & \text { Strong Auxiliary } \\ \text { ET } & \text { Expletive There } & \text { Spec } & \text { Specifier } \\ \text { Ex-phrase } & \text { Exclamatory Phrase } & \text { SPP } & \text { Subject Precedence Principle } \\ \text { F } & \text { Final Ending (in Korean) } & \text { S-subject } & \text { Sentence-Subject } \\ \text { FP } & \text { Final Ending Phrase/Projection of } & t & \text { Trace } \\ & \text { Functional Element } & \text { T } & \text { Tense } \\ i & \text { Index Signifying Coreference } & \text { T' } & \text { Tense Bar Projection } \\ \text { INFL } & \text { Inflection } & \text { TE } & \text { Transparency Effect } \\ \text { IP } & \text { Inflection Phrase } & \text { TP } & \text { Tense Phrase } \\ \text { LF } & \text { Lexical Form } & v P & \text { Small Verb Phrase } \\ \text { NegP } & \text { Negative Phrase } & \text { VP-1 } & \text { VP lack of VP-Subject, i.e. } \\ \text { NK } & \text { Nominative Case Marker } & & \text { VP minus NKP } \\ \text { NKP } & \text { Nominative Case Phrase } & \text { W-Aux } & \text { Weak Auxiliary } \\ \text { NumP } & \text { Number Phrase } & \text { Wh-phrase } & \text { Interrogative Word Phrase } \\ & & & \end{array}$

\section{References}

Abney, S. P. 1987. The English Noun Phrase in its Sentential Aspect [D]. PhD Dissertation. Cambridge: Massachusetts Institute of Technology.

Altmann, H. 1987. Zur Problematik der Konstitution von Satzmodi als Formtypen [A]. In J. Meibauer (ed.) Satzmodus zwischen Grammatik und Pragmatik [C]. Tübingen: Niemeyer, 22-56.

d'Avis, F. 2016. Different Languages: Different sentence types? On Exclamative Sentences [J]. Language and Linguistics Compass, 10(4):159-175.

Bierwisch, M. 1980. Semantic Structure and Illocutionary Force [A]. In J. R. Searle, F. Kiefer \& M. Bierwisch (eds.). Speech Act Theory and Pragmatics [C]. Dordrecht: D. Reidel Publishing Company, 


\section{Restructuring and the Proper Syntactic Analysis}

1-35.

Bolinger, D. 1977. Meaning and Form [M]. London: Longman.

Burzio, L. 1986. Italian Syntax: A government-binding theory [M]. Dordrecht: D. Reidel Publishing Company.

Cardinaletti, A. 1997. Subjects and Clause Structure [A]. In L. Haegeman (ed.). The New Comparative Syntax [C]. London: Longman, 33-63.

Chang, K. K. 2012. A Study on the Definiteness Effect in the Existential There-Construction [J]. The Journal of Modern British \& American Language \& Literature, 30(1):81-100.

Choe, H. S. 1988. Restructuring Parameters and Complex Predicates: A transformational approach [M]. Seoul: Hanshin Publishing Co.

Choe, H. S. 1994. Agreement and Existential Sentences in English [J]. Studies in Humanities, 6(1):25-59.

Choe, H. S. 2008. Some Empirical Problems of the Two Previous Approaches to Existential there [J]. Korean Journal of English Language and Linguistics, 8(1):93-117.

Chomsky, N. 1957. Syntactic Structures [M]. Hague: Mouton Publishers.

Chomsky, N. 1965. Aspects of the Theory of Syntax [M]. Cambridge: The MIT Press.

Chomsky, N. 1974. The Amherst Lecture [R]. Lecture Given at the 1974 Linguistic Institute, University of Massachusetts, Amherst; Université de Paris VII.

Chomsky, N. 1977. On Wh-Movement [A]. In P. Culicover, T. Wasow \& A. Akmajian (eds.). Formal Syntax [C]. New York: Academic Press, 71-132.

Chomsky, N. 1981. Lectures on Government and Binding [M]. Dordrecht: Foris Publications.

Chomsky, N. 1986. Barriers [M]. Cambridge: The MIT Press.

Chomsky, N. 1999. Some Notes on Economy of Derivations and Representation [A]. In R. Freidin (ed.). Principles and Parameters in Comparative Grammar [C]. Cambridge: The MIT Press, 417-454.

Chomsky, N. 1993. A Minimalist Program for Linguistic Theory [A]. In K. Hale \& S. J. Keyser (eds.). The View from Building 20 [C]. Cambridge: The MIT Press, 1-52.

Chomsky, N. 1995. The Minimalist Program [M]. Cambridge: The MIT Press.

Chomsky, N. 2000. The Minimalist Inquiries: The framework [A]. In R. Martin, D. Michaels \& J. Uriagereka (eds.). Step by Step [C]. Cambridge: The MIT Press, 89-155.

Chomsky, N. 2001. Derivation by Phase [A]. In M. Kenstowicz (ed.). Ken Hale: A life in language [C]. Cambridge: The MIT Press, 1-52.

Chung, H. M. 2009. Discourse Functions of English Existential there Construction with the Discourse Topic Management [J]. Korean Journal of Teacher Education, 25(3):147-166.

Cinque, G. 2006. Restructuring and Functional Heads: The cartography of syntactic structures [M] Oxford and New York: Oxford University Press.

Deal, A. 2009. The Origin and Content of Expletives: Evidence from selection [J]. Syntax, 12(4):285-362.

Erteschik-Shir, N. 1973. On the Nature of Island Constraints [D]. PhD Dissertation. Cambridge: Massachusetts Institute of Technology.

Farmer, A. K. 1984. Modularity in Syntax: A study of Japanese and English [M]. Cambridge: The MIT Press.

Fischer, O., A. van Kemenade, W. Koopman \& W. van der Wurff. 2014. The Syntax of Early English [M]. Cambridge: Cambridge University Press.

Freidin, R. \& R. A. Sprouse. 1999. Lexical Case Phenomena [A]. In F. Freidin (ed.). Principles and Parameters in Comparative Grammar [C]. Cambridge: The MIT Press, 392-416.

Fries, N. 1988. 1st Pragmatik Schwer über sogenante Exklamativsätze im Deutschen [J]. Deutsche Sprach, 16: 193-205.

Fukui, N. 1986. A Theory of Category Projection and Its Applications [D]. PhD Dissertation. Cambridge: Massachusetts Institute of Technology.

Grimshaw, J. 1979. Complement Selection and the Lexicon [J]. Linguistic Inquiry, 10(1):279-326.

Hale, K. 1980. Remarks on Japanese Phrase Structure: Comments on the papers on Japanese syntax [A]. MIT Working Papers in Linguistics [C], 2:185-203.

Hazout, I. 2004. The syntax of Existential Constructions [J]. Linguistic Inquiry, 35(2):393-430.

Heath, J. 2018. Dogon Existential (-Presentative) Proclitics: Syntax, semantics, evolution [J]. Lingua, 


\section{Hong-Pin Im}

213:78-90

Im, H. P. 2008. On the Real Nature of Scrambling in Korean [J]. Macrolinguistics, 2(1):157-186.

Im, H. P. 2018a. Restructuring in Korean 1 [M]. Seoul: Seoul National University Press.

Im, H. P. 2018b. Restructuring in Korean 2 [M]. Seoul: Seoul National University Press.

Kim, Y. H. 2008. Syntactic Nature of Wh-Word Structure: The condition and motivation of movement [A].

In Y. H. Kim, K. S. Kim, K. S. Moon (eds.). Syntax and Semantics of Wh-Interrogatives [C]. Seoul: Hankook Publishing Company, 1-48.

Kitagawa, Y. 1986. Subjects in Japanese and English [D]. PhD Dissertation. Amherst: University of Massachusetts.

Lakoff, G. 1987. Women, Fire, and Dangerous Things: What categories reveal about the mind [M]. Chicago: University of Chicago Press.

Lee, K. H. 2002. VP-Internal Subject Hypothesis and VP Preposing [J]. The New Studies of English Language and Literature, 23:156-172.

Lee, H. Y. 2012. Unaccusative Verbs and Unergative Verbs in Locative Inversion Constructions [J]. 21st Century English Language and Literature, 24(2):123-138.

Levin, B. 1993. English Verb Classes and Alternations: A preliminary investigation [M]. Chicago: University of Chicago Press.

Manzini, M. R. 1983. Restructuring and Reanalysis [D]. PhD Dissertation. Cambridge: Massachusetts Institute of Technology.

McFadden, T. 2004. The Position of Morphological Case in the Derivation: A study of the syntaxmorphology interface [D]. PhD Dissertation. Philadelphia: University of Pennsylvania.

Michaelis, L. A. 2001. Exclamative Constructions [A]. In M. Haspelmath, E. König, W. R. Öesterreicher \& W. Raible (eds.). Language Typology and Language Universals: An international handbook [C]. Berlin: Walter de Gruyter, 1038-1050.

Milsark, G. E. 1974. Existential Sentences in English [D]. PhD Dissertation. Cambridge: Massachusetts Institute of Technology.

Norvin, R. 1999. Featural Cyclicity and the Ordering of Multiple Specifiers [A]. In S. D. Epstein \& N. Hornstein. (eds.). Working Minimalism [C]. Cambridge: The MIT Press, 127-158.

Perlmutter, D. M. 1978. Impersonal Passives and the Unaccusative Hypothesis [A]. In Proceedings of the 4th Annual Meeting of the Berkeley Linguistics Society [C]. Berkeley: University of California, 157189.

Picallo, M. C. 1985. Restructuring Constructions [A]. NYU Working Papers in Linguistics [C]. New York: NYU.

Picallo, M. C. 1987. Opaque Domains [D]. PhD Dissertation. New York: The City University of New York.

Pollock, J. Y. 1989. Verb Movement, Universal Grammar and the Structure of IP [J]. Linguistic Inquiry, 20(3):365-424.

Quirk, R., S. Greenbaum, G. Leech \& J. Svartvik. 1985. A Comprehensive Grammar of the English Language [M]. London: Longman.

Radford, A. 1981. Transformational Syntax: A student's guide to Chomsky's extended standard theory [M]. Cambridge: Cambridge University Press.

Radford, A. 1988. Transformational Grammar: A first course [M]. Cambridge: Cambridge University Press.

Rizzi, L. 1982. Issues in Italian Syntax [M]. Dordrecht: Foris Publications.

Schütze, C. 2001. On the Nature of Default Case [J]. Syntax, 4(3):205-238.

Searle, J. R. 1989. How Performatives Work [J]. Linguistics and Philosophy, 12(5):535-558.

Speas, M. 1986. Adjunction and Projection in Syntax [D]. PhD Dissertation. Cambridge: Massachusetts Institute of Technology.

Sobin, N. 1997. Agreement, Default Rules, and Grammatical Viruses [J]. Linguistic Inquiry, 28(2):318-326.

Tateishi, K. 1994. The Syntax of 'Subjects' [M]. Tokyo: Kurosio Publishers. 